\title{
Pacto federativo e autonomia legislativa municipal
}

\author{
Federative pact and municipal legislative autonomy
}

Pacto federativo y autonomía municipal legislativa

Janaína Rigo Santin *
Jean Carlos Menegaz Bitencourt

\section{Resumo}

O presente artigo tem como objetivo analisar o pacto federativo brasileiro, bem como a autonomia municipal e a importância do município para a efetividade das políticas públicas, principalmente no que tange à autonomia legislativa. Ditas matérias são de suma importância para o municipalismo e para a análise do controle de constitucionalidade.

Palavras-chave: Federalismo. Município. Autonomia.

\section{Considerações Preliminares}

O artigo $1^{\circ}$ da Constituição Federal de 1988 proclama que a República Federativa do Brasil é formada pela união indissolúvel dos estados, dos municípios e do Distrito Federal. E, no artigo 18, o diploma constitucional refere expressamente que "a organização política administrativa da República Federativa do Brasil compreende a União, os Estados, o Distrito Federal e os Municípios, todos autônomos, nos termos desta Constituição".

Portanto, no mesmo espaço territorial e na mesma população, tem-se a incidência de

\footnotetext{
Pós Doutora em Direito pela Universidade de Lisboa. Advogada. Professora do Mestrado em Direito e do Doutorado e Mestrado em História da Universidade de Passo Fundo, Brasil. E-mail: janainars@upf.br.

* Mestrando em Direito pela Universidade de Passo Fundo - UPF, linha de Pesquisa Jurisdição Constitucional e Democracia. Passo Fundo. Rio Grande do Sul. Brasil. Bolsista do Prosup/Capes/UPF/Taxa. Procurador do Município de Lagoa Vermelha/RS.
}

Recebido em 20/03/2015 - Aprovado em 25/03/2015 http://dx.doi.org/10.5335/hdtv.15n.1.5279 
várias instâncias de poder governamentais, em que se constituem várias ordens estatais. No Brasil, pela sua característica de Estado Federado, "o poder não fica concentrado nas mãos de uma única pessoa jurídica de direito público, mas se reparte entre os entes coletivos que a compõem" (União, estados, Distrito Federal e municípios) (FERRARI, 2003, p. 53).

Assim, o Município integra a ordem administrativa e política brasileira, tendo reconhecida constitucionalmente a sua autonomia. O presente artigo pretende abordar os seguintes temas: federalismo e municipalismo, autonomia municipal e autonomia legislativa (lei orgânica e interesse local).

\section{Federalismo e o municipalismo}

O federalismo, inspirado na descentralização especial do poder, como instituído na Constituição dos Estados Unidos da América, "foi concebido como técnica de separação de centros de poder para reduzir os inconvenientes de uma excessiva concentração em um só ente político, flexibilizando-os de modo a atenderem às peculiaridades regionais de países com grandes territórios" assim como no Brasil (MOREIRA NETO, 2014, p. 35). Em verdade, nas palavras de José Nilo de Castro, "Estado integralmente centralizado não existe e jamais existiu, e que Estado totalmente descentralizado é muito difícil de conceber" (CASTRO, 2006, p. 23), sendo que a autonomia municipal somente é aplicável à coletividade local com relatividade, pois essa tem conformação com regras constitucionais, ou seja, enfrenta limites de competência.

Por força do artigo 60, parágrafo $4^{\circ}$, inciso I, da Constituição Federal, o federa- lismo constitui cláusula pétrea, imodificável por vontade do poder constituinte reformador. Prestigiou-se como princípio orientador do Estado o federalismo de cooperação (artigo 23, parágrafo único), outorgando-se ao Município, como ente federado, autonomia política constitucional, organizacional, financeira, legislativa e administrativa, dentro de regras rígidas de repartição de competências.

As cláusulas pétreas contêm uma proibição de ruptura de princípio, de forma que haverá de ser reconhecida como inconstitucional qualquer medida que altere ou busque atingir o pacto federativo, inclusive aquela que acarrete uma atenuação significativa dos princípios listados pelo constituinte.

Antônio Machado Pauperio entende que o "Município é a célula territorial do Estado". Citando Rui Barbosa, enfatiza que

[...] não há corpo sem células. Não há Estado sem municipalidades. Não pode existir matéria vigente sem vida orgânica. Não se pode imaginar existência de nação, existência de povo constituído, existência de Estado, sem vida municipal (BARBOSA, [s. d] apud PAUPERIO, 1971, p. 40).

No Estado Federal, as competências da União e as atribuições dos demais entes federativos são estabelecidas na Constituição, mediante rígido processo de distribuição de competências. Não existe hierarquia entre os entes federativos (União, Estados e Municípios), "porque a cada esfera de poder corresponde uma competência determinada" constitucionalmente (DALLARI, 2011, p. 255).

Essa forma de Estado, como bem refere Dallari, assegurou oportunidades mais 
amplas de participação do cidadão no poder político, pois aqueles que não obtiverem ou não desejarem a liderança federal poderão ter acesso aos poderes locais, mais próximos dos cidadãos. Assim, o Estado Federal é mais democrático, já que "assegura maior aproximação entre governantes e governados", pois "o povo tem maior acesso aos órgãos do poder local" (DALLARI, 2011, p. 256). Além disso, a organização federativa favorece a preservação das características e identidades locais, ao mesmo tempo em que promove a interação entre sociedade civil e sociedade política. Trata-se, portanto, de uma "arma a serviço da descentralização, da democracia e da participação dos cidadãos no exercício do poder político" (SANTIN; FLORES, 2006, p. 56-69).

Assim, a Federação, como estratégia de descentralização do poder político, envolve uma repartição rígida de competência entre o órgão do poder central, denominado União, e as expressões das organizações regionais, conhecidas por estados-membros, e como terceiro nível de competências, no modelo federalista brasileiro: o município (STRECK; MORAIS, 2008, p. 171).

$\mathrm{O}$ federalismo brasileiro, apesar de ter se baseado no modelo federalista norte-americano, foi além, pois acrescido aos estados-membros também elevou o município à categoria de ente federativo. Entretanto, essa situação é muito criticada na doutrina brasileira, pois, na prática, o modelo brasileiro ainda é muito centralizador. Celso Ribeiro Bastos critica a opção do legislador constituinte de 1988, por entender que deveriam ter sido descentralizadas ainda mais competências aos municípios:
O traço principal que marca profundamente a nossa já capenga estrutura federativa é o fortalecimento da União relativamente às demais pessoas integrantes do sistema. É lamentável que o constituinte não tenha aproveitado a oportunidade para atender ao que era o grande clamor nacional no sentido de uma revitalização do nosso princípio federativo. O Estado brasileiro na nova Constituição ganha níveis de centralização superior à maioria dos Estados que se consideram unitários e que, pela via de uma descentralização por regiões ou por províncias, consegue um nível de transferência das competências tanto legislativas quanto de execução muito superior àquele alcançado pelo Estado Brasileiro (BASTOS, 1995, p. 258).

Em verdade, o Federalismo deve situar-se entre a centralização do poder, presente nos Estados Unitários, e a dispersão do poder existente nas confederações. Preserva-se constitucionalmente a autonomia dos entes federativos, definindo competência aos entes regionais que o compõem, mas a soberania é atributo apenas da União. Os estados-membros passam a se auto-organizar mediante constituições estaduais, com a presença de um órgão legislativo representativo de cada um deles, que é o Senado Federal. E, na mais alta cúpula do Poder Judiciário, constitui-se um tribunal constitucional independente, que é o Supremo Tribunal Federal, com a função precípua de zelar pela preservação da ordem jurídica (BARROSO, 1982).

Talvez, o maior problema do federalismo brasileiro e suas distorções esteja na sua matriz teórica, o modelo de federalismo dos Estados Unidos da América. Enquanto o Brasil Imperial era um Estado Unitário altamente centralizado, com o agigantamento das funções do Imperador, os Estados Unidos da América formaram a sua proposta fe- 
deralista, a partir de um pacto de unificação de entes independentes, com características e identidades próprias, soberanos e confederados, que eram as treze colônias americanas ${ }^{1}$. No Brasil, o Poder Moderador exercido pelo Imperador, que ainda representava o Poder Executivo, tinha amplas possibilidades de intervenção nos demais poderes (Legislativo e Judiciário), bem como, também, poderia intervir nas províncias e nas municipalidades, dominadas por uma política coronelística pautada em troca de favores entre governos provinciais e municipais.

O Federalismo dos Estados Unidos deu-se como um projeto nacional para o fortalecimento de suas 13 colônias (doravante chamadas estados-membros) ante a comunidade internacional. Já o Federalismo brasileiro se deu como um modelo teórico ideal, formulado pela importação do modelo norte-americano na Constituição Republicana de 1891, que copiou até o nome do país na época, chamado constitucionalmente de Estados Unidos do Brasil. Implantou-se, formalmente, o federalismo e a descentralização política em um Brasil, na época, sem cultura democrática, com predomínio de analfabetos, pautado em uma política altamente centralizada e coronelística de âmbito regional. ${ }^{2}$ Por certo, tais características históricas influenciam, ainda hoje, nas dificuldades da efetiva descentralização de poder e de recursos no Brasil.

O federalismo tem importantes princípios que lhe dão substância, sem os quais há o seu desvirtuamento, que são: “Estado democrático de direito, república, não centralização, subsidiariedade, liberdade e pluralismo" (CORRALO, 2011, p. 45). Além dos princípios essenciais, para configur-se como do Estado federal, esse deve apresentar, concomitantemente, as seguintes características: a) proeminência de uma Constituição escrita, que disponha sobre a repartição de competências entre os entes federados, resguarde as suas autonomias, considere-os numa situação de igualdade e discipline as possibilidades de intervenção, resguardando a soberania para a federação; b) pluralidade de ordens jurídicas e esferas governamentais autônomas, nas três funções estatais, sob a égide da não-centralização ou policentrismo; c) participação dos entes federados na formação da vontade nacional, isto é, na criação e alteração da Constituição e no processo legislativo federal; d) existência de um órgão judicial para o resguardo da Constituição e para dirimir conflitos entre os entes federados; e) proibição de secessão; e, f) pluralidade de cidadanias (CORRALO, 2009, p. 142).

O federalismo cooperativo contemporâneo não se contenta apenas com a simples relação de colaboração entre entes federados. Reclama uma atuação parceira na solução dos problemas sociais e econômicos (artigo 23, da Carta Magna), pois a atuação conjunta é requisito indispensável para alcançar os objetivos fundamentais da Federação Brasileira, previstos expressamente no texto constitucional.

No entanto, é preciso ressaltar que o federalismo contemporâneo brasileiro rompeu com a teoria federalista tradicional para se tornar responsável pela ampliação dos laços relacionais entre os municípios e o governo federal. O que se percebe é que a grande centralização de recursos na União e a grave crise financeira dos Estados-membros deslocam para o governo federal as reivindicações das municipalidades a respeito de serviços públicos essenciais, ou seja, "serviços e obras de nítido interesse local" (HORTA, 1957, p. 81).

A partir da Carta Magna de 1988, percebeu-se uma importante descentralização 
na prestação dos serviços públicos, os quais ficaram, em grande parte, com atribuição municipal. Entretanto, não houve a correspondente repartição de tributos da União para os Municípios, a fim de que pudessem fazer frente a todas as suas atribuições constitucionais. Assim, o município brasileiro tem muitos ônus e poucos bônus. Assume todas as responsabilidades na organização da cidade, dos serviços públicos locais, com atribuições político-administrativas abrangentes a todo o território do município. Mas, quando se quantifica a repartição tributária nos entes federativos, verifica-se o quanto o Município é prejudicado, em uma voracidade centralizadora de recursos por parte da União.

Percebe-se através de uma interpretação sistemática da Constituição Federal brasileira, analisando conjuntamente os dispositivos que tratam das competências próprias para a instituição de tributos, que o governo da União mantém a concentração dos tributos, em que pese os encargos estarem se descentralizando para as outras unidades federativas. Tomando em consideração tal assertiva, revela-se o desequilíbrio vertical na Federação, no que tange à titularidade do tributo, ou como denomina Sérgio Prado (2006), exsurge-se a 'brecha vertical', consistente na necessidade das transferências da União para os demais entes, de quantias vultosas, a fim de aumentar a capacidade de gasto dos governos estaduais e municipais, tendo em vista que apenas com sua receita própria tais membros federativos não conseguiriam perfazer suas competências materiais insculpidas na Constituição Federal, quedando-se estagnados em seu desenvolvimento. (GIROLDO; KEMPFE, 2012, p. 3-20). ${ }^{3}$
A cada esfera de competência deveria ser atribuída renda própria, o que não ocorre em nosso País. Esse é um ponto de grande importância e que só recentemente começou a ser tratado. A experiência demonstra que dar-se competência é o mesmo que atribuir encargos/responsabilidades. É indispensável, portanto,

[...] que se assegure a quem tem os encargos uma fonte de renda suficiente, pois do contrário a autonomia política torna-se apenas nominal, pois não é possível agir com independência quem não dispõe de recursos próprios (DALLARI, 2011, p. 255).

O pacto federativo brasileiro, no que tange à repartição tributária, é por demais injusto, pois o município é a grande mola precursora para o desenvolvimento do País. A grande maioria dos municípios brasileiros encontra-se mergulhada em um colapso financeiro devido à péssima repartição de receitas. Portanto, sem a ajuda do governo federal, por meio de transferências voluntárias em convênios, os municípios não sobreviveriam, dependendo de emendas parlamentares (que, diga-se de passagem, deveriam ser extintas, já que são práticas eminentemente patrimonialistas, contrárias à isenção e à isonomia que deve haver em um Estado Democrático de Direito) e do fundo de participação municipal.

Dessa forma, conclui-se que o federalismo brasileiro pós 1988, apesar de o constituinte ter sido cauteloso, trouxe progresso em agregar autonomia e independência ao Município em relação aos outros entes da Federação. Mas necessita, ainda, de uma alteração profunda na questão da repartição das receitas públicas (federalismo fiscal). 


\section{Autonomia Municipal}

Conforme referido, e apesar de todas as contradições, andou bem o constituinte ao incluir o município como parte integrante da federação. A Constituição Federal reparte as competências entre os entes federados (União, Estados, Municípios e Distrito Federal) tendo como critério a predominância do interesse, nacional, regional ou local.

Sobre a autonomia local, escreve Norberto Bobbio:

[...] o que caracteriza e a coloca num plano diferente é o fato de que a autonomia local, mesmo quando não se manifesta como autonomia política, não aparece como uma derivação da organização administrativa do Estado. Ela transcende o quadro conceptual de mera Descentralização administrativa e se liga, como já foi sublinhado, à temática da liberdade [...] (1988, p. 335).

Alexandre de Moraes ensina que:

Desta forma, o município auto-organiza-se através de sua Lei Orgânica Municipal e, posteriormente, por meio da edição de leis municipais; autogoverna-se mediante a eleição direta de seu prefeito, vice-prefeito e vereadores, sem qualquer ingerência dos Governos Federal e Estadual; e finalmente, auto-administra-se, no exercício de suas competências administrativas, tributárias e legislativas, diretamente conferidas pela Constituição Federal (2002, p. 274).

O princípio da autonomia municipal deriva do basilar princípio republicano e assegura aos municípios os efeitos de representatividade e da relação de administração. Desse modo, a característica fundamental da Carta Magna de 1988 consiste na ampliação da autonomia municipal no tríplice aspecto: político, administrativo e financeiro (MEIRELLES, 1988, p. 88).
Para Manoel Carlos de Almeida Neto, os Municípios receberam o reconhecimento

[...] constitucional de sua autonomia e capacidade de auto-organização, mediante a elaboração de lei orgânica própria, além de sua capacidade de autogoverno, autolegislação e autoadministração (2010, p. 81).

Para Paulo Bonavides:

Faz-se mister assinalar desse modo o significativo decisivo, inédito e inovador que assume o art. 18 da Constituição vigente. Esse artigo inseriu o município na organização político-administrativa da República Federativa do Brasil, fazendo com que ele, ao lado do Distrito Federal, viesse a forma aquela terceira esfera de autonomia, cuja presença, nos termos em que se situou, altera radicalmente a tradição dual do federalismo brasileiro, acrescido agora de nova dimensão básica (BONAVIDES, 2004, p. 345).

Nesse contexto, não há dúvida de que a Constituição Federal, em seus artigos $1^{\circ}$ e 18, elevou e reconheceu o município como ente federativo, delegando-lhe a autonomia, cumprindo assim a exigência básica do Estado federal: "a repartição regional dos poderes autônomos" (SANTIN; FLORES, 2006, p. 56).

Ao se elevar o município a ente federativo, facilitou-se a descentralização da prestação de serviços públicos, bem como se aproximou a população ao poder público municipal.

\section{Competência municipal}

A competência constitucional do Município é concebida mediante o critério do interesse predominante e não exclusivo, porque "não há interesse municipal que não o seja reflexamente da União e do estado-membro, como também, não há interesse 
regional ou nacional que não ressoe nos municípios, como partes integrantes da Federação brasileira" (MEIRELLES, 1998, p. 104).

Assim, a

[...] repartição de competência é a predominância do interesse, cabendo à União as matérias de interesse nacional ou geral, aos Estados as matérias de interesse regional e ao Município as de interesse local (FERRARI, 2003, p. 54).

O mecanismo de distribuição de competências "pode assumir estratégias diversas, adotando a expressão das competências de um dos entes federados e deixando as sobrantes ou residuais ao outro ou, ainda, pode-se adotar a técnica do esgotamento explícito das competências próprias de cada ente federado" (STRECK; MORAIS, 2008, p. 172). Percebe-se que a repartição de competências na Constituição Federal de 1988 buscou o equilíbrio, uma tendência atual do federalismo que se fundamenta na repartição de competência concorrente, em que se atribui determinada matéria legislativa e material a mais de um ente político. Pela repartição, proporciona-se maior equilíbrio nas ações, nos deveres, nos direitos e nas responsabilidades dentro da estrutura federal. Assim, nem a União, nem os Estados-membros, nem os municípios têm, por si só, a supremacia das competências que, reguladas rigidamente pela Constituição Federal e seguidas pela Constituição Estadual e pela Lei Orgânica Municipal, dão equilíbrio entre as entidades políticas e darão a concepção do federalismo que é determinado pelo constituinte.

Hely Lopes Meirelles enumera, não taxativamente, as atribuições mínimas para o exercício da autonomia municipal:
A atual Constituição da República, além de inscrever a autonomia como prerrogativa intangível do Município, capaz de autorizar até a intervenção federal, para mantê-la e restaurá-la, quando postergada pelo Estado-membro (art. 34, VII, " $c$ "), enumera, dentre outros, os seguintes princípios asseguradores dessa mesma autonomia: a) poder de auto-organização; eletividade do prefeito, do vice-prefeito e dos vereadores e legislação sobre assuntos de interesse local; b) administração própria, organização dos serviços públicos locais e ordenação do território municipal; c) decretação de tributos e aplicação das rendas municipais (arts. 29 e 30) (1988, p. 88).

A autonomia municipal constitui verdadeiro direito público subjetivo do Município e, como tal, é passível de ser defendido judicialmente por todo o aparato processual disponibilizado pelas regras vigentes, oponíveis a qualquer poder, órgão, autoridade pública ou particular que impeça ou dificulte o seu exercício. Um dos mecanismos é o disposto no artigo 34, inciso VII, letra "c", que é a possibilidade de intervenção federal nos Estados ou Distrito Federal sempre que constatado ataque à autonomia municipal.

Para analisar as competências definidas na Constituição aos Municípios, o estudo dos artigos $1^{\circ}, 18,23,24,29,30,39,144$ (parágrafo $8^{\circ}$ ), 156, 165, 182, 198 e 211, todos da Constituição Federal, é imprescindível.

O conhecimento das competências municipais permite verificar a autonomia dos municípios como ente federado, bem como a posição atualmente ocupada pelas municipalidades, conforme sua autonomia política, auto-organizatória, administrativa, legislativa e financeira. O presente artigo dará ênfase à autonomia legislativa, que será abordada na sequência. 


\section{Autonomia legislativa municipal}

Como bem refere José Afonso da Silva, a autonomia municipal está assente na capacidade normativa própria, ou seja, capacidade de autolegislação, mediante a competência para elaborar leis e regramentos municipais sobre áreas que são reservadas à sua competência exclusiva e suplementar (SILVA, 2009, p. 641).

A autonomia municipal é a faculdade que o Município tem, assegurada pela Constituição da República, de auto-organizar-se politicamente, por meio de lei própria (Lei Orgânica Municipal), de autogovernar-se, de legislar, originária ou supletivamente, sobre assuntos de interesse local e de auto-administrar-se, gerindo seus próprios negócios e serviços públicos locais e dispondo livremente sobre eles, respeitados o sistema constitucional das competências e as restrições que a mesma Constituição Federal lhe impõe.

A função legiferante, ou seja, o poder de constituir normas jurídicas num ordenamento jurídico municipal, é autonomia importantíssima para que ocorra desenvolvimento e adoção de políticas públicas locais eficazes e conforme o interesse local.

Cabe referir que o Código Civil definiu o Município como pessoa jurídica de direito público interno (artigo 41, inciso III, do Código Civil), e como tal responde por atos que lhe dizem respeito, tanto administrativa quanto judicialmente. Nos dois próximos tópicos será detalhada a autonomia legislativa municipal, no que se refere à edição da Lei Orgânica Municipal e às demais competências legislativas de interesse local.

\section{Lei Orgânica Municipal}

O artigo 29 da Constituição Federal disciplina que os Municípios brasileiros reger-se-ão por Lei Orgânica elaborada pelas Câmaras Municipais, que pode ser chamada de "Constituição Municipal", já que vai determinar toda a organização política, financeira e administrativa do Município e os direitos de seus cidadãos, observados os limites constitucionais previstos nas Constituições Federal e Estadual.

Para Hely Lopes Meireles, a disposição contida no artigo 29 da Constituição Federal, “com a permissão de o Município elaborar sua própria Lei Orgânica", expressa a capacidade de auto-organização de seus poderes (Executivo e Legislativo), competências, atribuições e serviços públicos, atingindo o ápice da autonomia política municipal. Entretanto, deverá sempre respeitar os dispositivos constitucionais federais e estaduais (MEIRELLES, 1998, p. 89).

Ela é uma espécie de Constituição municipal. Cuidará de discriminar a matéria de competência exclusiva do Município, observadas as peculiaridades locais, bem como a competência comum que a Constituição lhe reserva juntamente com a União, os Estados e o Distrito Federal (art. 23). Indicará, dentre a matéria de sua competência, aquela que lhe cabe legislar com exclusividade e a que the seja reservado legislar supletivamente (SILVA, 2009, p. 642).

A Constituição Federal indicou o conteúdo básico da Lei Orgânica, que terá que compreender normas sobre: a) posse de prefeito e dos vereadores e seu compromisso; b) inviolabilidade dos vereadores por suas opiniões, palavras e votos no exercício do 
mandato e na circunscrição do município; c) proibições e incompatibilidades, no exercício da vereança, similares, no que couber, ao disposto nessa Constituição para os membros do Congresso Nacional e na Constituição do respectivo estado para os membros da Assembleia Legislativa; d) organização das funções legislativas e fiscalizadoras da Câmara Municipal; e) cooperação das associações representativas no planejamento municipal; f) iniciativa popular de projetos de lei de interesse específico do município, da cidade ou de bairros, por meio de manifestação de, pelo menos, cinco por cento do eleitorado (artigo 29, incisos III, VIII, IX, XI, XII e XIII, da Constituição Federal de 1988).

$\mathrm{Na}$ "Lei Orgânica deve estar prevista competência municipal para editar leis complementares e leis ordinárias municipais". Ou seja, "necessário se faz regular o processo legislativo para disciplinar a matéria municipal, exigindo-se quórum de maioria absoluta para aquelas que regulam" normas tributárias, de obras/edificações e plano diretor, assim como uso e ocupação do solo, o estatuto do servidor público municipal, a divisão territorial do Município e outras matérias de maior vulto. As matérias que, "pela natureza, não precisem de lei complementar, podem ser editadas por lei ordinária, com o quórum de maioria simples, como as leis orçamentárias" e aquelas que "tratarem dos serviços públicos locais" (COSTA, 2014, p. 139).

Dessa forma, a prerrogativa de auto-organização é resultado de um amadurecimento acerca do papel que o município deve desempenhar no contexto federativo, possuindo ampla autonomia para disciplinar as matérias elencadas nos incisos do artigo 29 da Constituição Federal.
Importante referir que, caso os dispositivos da Lei Orgânica venham a infringir os princípios da Constituição Federal e da Constituição Estadual, também estão sujeitos ao controle concentrado de constitucionalidade tanto no Supremo Tribunal Federal, com a Arguição de Descumprimento de Preceito Fundamental e também nos Tribunais de Justiça Estaduais, com as Ações Diretas de Constitucionalidade.

\section{Autonomia normativa (interesse local)}

O princípio constitucional da autonomia normativa concede aos municípios a atribuição de autolegislação, por meio do poder de elaboração de leis municipais sobre áreas que são reservadas à sua competência exclusiva, suplementar e comum, todas disciplinadas na Constituição Federal.

Reza o artigo 30, inciso I, da Carta Magna, que compete aos municípios legislar sobre assuntos de interesse local, o qual necessita ser aprofundado, em face da imprecisão do termo "interesse local".

Não se trata de uma competência exclusiva, até porque em uma sociedade globalizada é muito difícil encontrar alguma coisa que seja de interesse "exclusivo" de algum ente federativo. $\mathrm{O}$ conceito chave utilizado pela Constituição para definir a área de atuação do município é o interesse "predominante local" (Constituição Federal de 1988, artigo 30), ou seja, os que entendem imediatamente às suas necessidades imediatas, e mediatamente às necessidades gerais.

O conceito de interesse local, "se por um lado pode gerar a perplexidade diante de situações ambíguas, onde se entrelaçam" 
(interesse local versus interesse regional), por outro, "oferece uma elasticidade que permite uma evolução da compreensão do texto constitucional diante da mutação por que passam certas atividades e serviços" (BASTOS, 1995, p. 275). Ou seja, não há dúvida de que há predominância do interesse municipal, no tempo e no espaço, no que diz respeito a serviços públicos.

A técnica utilizada para determinar a área de competência municipal por nosso legislador constituinte revela sabedoria, pois é praticamente impossível o levantamento de todas as funções passíveis de serem desempenhadas por um grupo comunitário em proveito de seus membros, assim como é impossível levantar todas as atribuições cabíveis a um grupo comunitário municipal, não se pode, portanto enumerar de forma exaustiva a competência municipal (FERRARI, 2003, p. 59).

Não há dúvida, o Município, por estar mais perto do cidadão, o qual serve de forma direta e frequente, deverá adequar-se às condições e necessidades locais. Os munícipes serão sempre os maiores interessados na solução dos problemas locais, por sentirem os efeitos da boa ou da má qualidade na prestação dos serviços públicos essenciais, como saúde, educação, obras de infraestrutura, cultura e assistência social, entre outras.

O interesse local traduz-se em todos os assuntos do Município, mesmo em que ele não fosse o único interessado, deve que seja o principal. É a sua predominância; tudo que repercute direta e imediatamente na vida municipal é de interesse local, segundo o dogma constitucional, havendo, por outro lado, interesse (indireta e mediatamente) do Estado e da União. Impõe-se a assertiva à vista do fenômeno da descentralização (CASTRO, 2006, p. 24).
Assim, a autonomia municipal contemplada no texto constitucional, ao visar à descentralização dos poderes, forneceu ao núcleo básico da estrutura socioadministrativa da federação diversas competências, o que trouxe as discussões sobre direitos fundamentais, em geral, para o âmbito local. Elevou-se

[...] o poder local para o âmbito jurídico e político brasileiro, a qual busca aliar a descentralização com a participação popular no exercício do poder político, inaugurando uma forma mais democrática de gestão pública, aliada aos principais objetivos da Constituição Federal e do Estado democrático de direito (SANTIN; FLORES, 2006, p. 65).

O município também possui competência suplementar, conforme dispõe o artigo 30, inciso II, da Carta Magna, quando refere que compete ao Município "suplementar a legislação federal e a estadual no que couber". É interessante frisar que a forma que deve ser interpretado este dispositivo é no sentido de "admitir que essa suplementação é apenas complementar, ou seja, tem o sentido de adaptação da legislação federal e estadual às peculiaridades ou à realidade da comuna" (FERRARI, 2003, p. 57). Exemplo típico de competência suplementar é a atribuição municipal para regrar o horário de funcionamento do comércio local, "desde que não infrinjam leis estaduais ou federais válidas" (Súmula 419 do Supremo Tribunal Federal).

Consoante à supremacia da Constituição Federal no ordenamento jurídico nacional, a legislação municipal deverá estar congruente com os princípios e disposições de observância obrigatória dos entes federados, assim como os princípios oriundos da Consti- 
tuição Estadual. Além disso, todas as leis municipais complementares e ordinárias deverão observar o que dispõe a Lei Orgânica daquele Município, hierarquicamente superior.

Dessa forma, a não observância da hierarquia das normas possibilitará o controle por meio do controle difuso de constitucionalidade e também controle concentrado (efeito erga omnes).

\section{Consideraçoes finais}

O importante modelo adotado pela Carta Magna Brasileira de 1988 visa ao fortalecimento da autonomia municipal, e já está incorporado no país, pois a descentralização administrativa tem aberto o caminho para uma gestão mais democrática, pautada na participação dos munícipes a fim de buscar atender a todas as especialidades locais.

Pelo presente artigo restou demonstrado que a autonomia municipal consiste em quatro capacidades outorgadas aos Municípios pela Constituição Federal - capacidade de auto-organização, de autogoverno, de autoadministração de seus negócios e de autolegislação, com destaque para esta última.

Negar ao município a condição de ente federativo é negar vigência à própria Constituição, pois assim foi expressamente reconhecido pelo constituinte.

É no município que todos os cidadãos vivem e é da satisfação de suas necessidades básicas que deflui o bem-estar do país. No entanto, a comunidade local está inserida num contexto maior, que é a comunidade estadual e federal. As dificuldades/carências locais projetam-se nesse contexto mais amplo, "o que faz com que também haja interesse estadual e federal no bom andamento e no desenvolvimento das entidades locais". Dessa forma, "carências ou deficiências locais devem ser supridas pelos órgãos dos governos estadual e federal, porque, em última análise, a receita federal e a estadual são constituídas a partir de bases municipais" (FERRARI, 2003, p. 63).

No Brasil, o governo e a administração de cada município correspondem ao que seu povo, representantes e munícipes, estabelecer nas leis votadas pelas suas Câmaras. $\mathrm{O}$ município pode governar-se e administrar-se como bem lhe parecer, sem interferência de outros entes (União e Estados-membros), contanto, naturalmente, que não se afaste dos princípios da Constituição Federal.

O município é detentor de autonomia política, consubstanciado no poder de eleger prefeito, vice-prefeito e vereadores; assim como tem poder de auto-organização e capacidade para a elaboração de sua Lei Orgânica. O artigo 30 da Constituição da República Federativa do Brasil de 1988, quando utiliza o termo interesse local, não limita as autonomias normativa e administrativa municipais ao interesse exclusivo do município, embora o interesse local seja o limite de atuação do município nessas duas esferas.

Portanto, o interesse local está adstrito às considerações e às características peculiares de cada localidade. Pode-se afirmar que sua característica é a predominância do interesse do município sobre o do estado ou da União, sem esquecer de que o interesse local também serve de limitador da autonomia municipal, especialmente no âmbito legislativo e administrativo, não podendo 
extrapolá-lo, sob pena de ferir a autonomia dos demais entes federativos.

A autonomia municipal e seus limites na organização político-administrativa da República Federativa do Brasil é objeto de inúmeras discussões doutrinárias, pois se trata de um tema amplo e inovador, que cuida diretamente dos interesses e da repartição de competências entre os entes federados. Por certo, a maior necessidade de evolução nessa área é uma urgente reforma tributária, capaz de contemplar um federalismo fiscal mais justo e equânime, com maior descentralização de recursos às unidades federativas mais próximas dos cidadãos. Afinal, são os municípios os maiores responsáveis pela prestação dos serviços públicos garantidores dos direitos fundamentais.

Assim, o papel das municipalidades no Estado Brasileiro é indispensável, pois é por meio de suas competências legislativas que as administrações municipais dão efetividade às políticas públicas.

\section{Abstract}

This article aims to analyze the federative pact and municipal autonomy and the importance of the City to the effectiveness of public policies, especially with regard to legislative autonomy. Said matters are of importance for the Municipalism as well as for analysis of judicial review.

Keywords: Federalism. Municipality. Autonomy.

\section{Resumen}

Este artículo tiene como objetivo analizar el pacto federal brasileño y la autonomía municipal y la importancia de la Municipalidad para la eficacia de las políticas públicas, especialmente en lo que respecta a la autonomía legislativa. Dichos materiales son de suma importancia para el enfoque municipal y el análisis de la revisión judicial.

Palabras clave: Federalismo. Municipio. Autonomía.

\section{Notas}

O processo americano de federalização estava voltado para uma centralização do poder, com a imposição de procedimentos comuns, uma vez que o que existia na época da guerra de independência era uma confederação de laços extremamente frágeis. A Convenção de Filadélfia teve, inicialmente, o propósito de revisar os artigos da Confederação, cujas regras começaram a ser desrespeitadas, por exemplo, quando se previa unanimidade dos Estados para aprovação de decisões. Durante esse processo de revisão, percebeu-se a formação da vontade de se fazer uma Constituição para uma federação. À época da união confederada, Madison havia escrito um ensaio político intitulado "Os vícios do sistema político nos Estados Unidos" e pretendia apresentar na Convenção um plano de governo nacional, através do Governador da Virgínia, Edmund Randolph, que já expressara desdém pela forma confederada de governo, por não garantir a liberdade dos cidadãos e o bem-estar geral. Este plano pedia a Constituição de um governo nacional com um legislativo, um executivo e um judiciário supremos. Ainda que se constatem estes princípios na Constituição Americana, o plano dos virginianos foi muito debatido e muito retocado durante os trabalhos da Convenção. Após muitos debates, a existência de um governo nacional foi aprovada dentro de uma comissão por seis votos contra um. A necessidade da continuidade do comércio entre os Estados foi um dos grandes e principais moti- 
vos para que se buscasse a paz, por meio de uma União mais sólida (PINTO FILHO, 2002, p. 50).

2 Nesse sentido ver: (SANTIN, 2007, p. 72-78).

3 Alguns autores questionam se o Brasil seria mesmo uma federação, com uma repartição tributária tão injusta. "Porque $68 \%$ de todos os tributos arrecadados no Brasil (nada menos que $\mathrm{R} \$ 1,7$ trilhão em 2013) vão direto para o governo federal, que todo mês redistribui um percentual para os Estados e municípios. No fim das contas, acaba assim: $58 \%$ da arrecadação ficam em Brasília, $24 \%$ nos Estados e 18\% nos municípios" (GERMANO, 2014).

\section{Referências}

ALMEIDA NETO, Manoel Carlos de. O Novo Controle de Constitucionalidade Municipal. Rio de Janeiro: Forense, 2010.

BARROSO, Luis Roberto. Direito Constitucional Brasileiro: o problema da federação. Rio de Janeiro: Forense, 1982.

BASTOS, Celso Ribeiro. Curso de Direito Constitucional. 15. ed. São Paulo: Saraiva, 1995.

BOBBIO, Norberto. Dicionário de política. Trad. Carmen C. Varriale, Gaetano Lo Mônaco, João Ferreira, Luiz Guerreiro Pinto Cascaes e Renzo Dini. 11 ed. Brasília: UnB, 1998.

BONAVIDES, Paulo. Curso de Direito Constitucional. 15. ed. São Paulo: Malheiros, 2004.

CASTRO, José Nilo de. Direito Municipal Positivo. 6. ed. Belo Horizonte: DelRey, 2006.

CORRALO, Giovani da Silva. Curso de Direito Municipal. São Paulo: Atlas, 2011.

. Município: Autonomia na Federação

Brasileira. Curitiba: Juruá Editora, 2009.

COSTA, Nelson Nery. Curso Municipal Brasileiro. 6. ed. Rio de Janeiro: Forense, 2014.

DALLARI, Dalmo de Abreu. Elementos de Teoria Geral do Estado. 30. ed. São Paulo: Saraiva, 2011.

FERRARI, Regina Maria Macedo Nery. Controle da Constitucionalidade das Leis Municipais. 3. ed. São Paulo: Revista dos Tribunais, 2003.
GERMANO, Paulo. Por que você paga tanto imposto e recebe tão pouco de volta: entenda o pacto federativo. Jornal Zero Hora. 13 dez. 2014. Disponível em: http://zh.clicrbs.com.br/ rs/noticias/proa/noticia/2014/12/por-que-voce-paga-tanto-imposto-e-recebe-tao-pouco-de-volta-entenda-o-pacto-federativo-4662687. html. Acesso em: 5 mar. 2015.

GIROLDO, Camila Nayara Giroldo; KEMPFE, Marlene Kempfe. Autonomia municipal e o federalismo fiscal brasileiro. Revista de Direito Público, Londrina, v. 7, n. 3, p. 3-20, set./dez. 2012.

HORTA, Raul Machado. Problema do federalismo brasileiro. Revista da Faculdade de Direito, Belo Horizonte, ano IX, out. 1957.

MEIRELLES, Hely Lopes. Direito Municipal Brasileiro. 10. ed. São Paulo: Malheiros Editores, 1998.

MORAES, Alexandre de. Direito Constitucional. 12. ed. São Paulo: Atlas, 2002.

MOREIRA NETO, Diogo de Figueiredo Moreira. Curso de Direito Administrativo. 16. ed. Rio de Janeiro: Forense, 2014.

PAUPERIO, Antônio Machado. Teoria Geral do Estado. 6. ed. Rio de Janeiro: Forense, 1971.

PINTO FILHO, Francisco Bilac Moreira. A intervenção federal e o federalismo brasileiro. Rio de Janeiro: Forense, 2002.

SANTIN, Janaína Rigo; FLORES, Deborah Hartmann. A evolução histórica do município no federalismo brasileiro, o poder local e o estatuto da cidade. Revista Justiça do Direito (UPF), Passo Fundo, v. 20, n. 1, p. 56-69, 2006.

SANTIN, Janaína Rigo. O Tratamento Histórico do Poder Local no Brasil e a Gestão Democrática Municipal. Estudos Jurídicos (UNISINOS), São Leopoldo, v. 40, p. 72-78, 2007.

SILVA, José Afonso da. Curso de Direito Constitucional Positivo. 32. ed. São Paulo: Malheiros Editores, 2009.

STRECK, Lenio Luiz; MORAIS, José Luis Bolzan. Ciência Política e Teoria do Estado. 6. ed. Porto Alegre: Livraria do Advogado, 2008. 